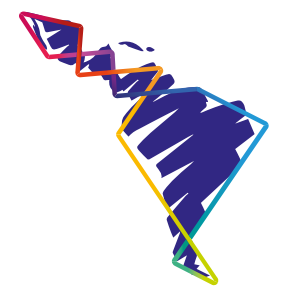

\title{
Mujeres y cárcel: Ser migrante e indígena en el norte de Chile
}

\section{Women and jail: being migrant and indigenous in northern of Chile}

\author{
Francisca Fernández Droguett ${ }^{1}$
}

\begin{abstract}
Resumen
Este artículo tiene por objetivo caracterizar el perfil sociocultural de las mujeres indígenas extranjeras privadas de libertad en las regiones de Arica-Parinacota, Tarapacá y Antofagasta, del norte de Chile. Para ello se llevó a cabo una investigación cualitativa mediante la realización de entrevistas semiestructuradas. En cuanto a los resultados, la mayoría de las mujeres proceden de las regiones de Puno, Perú, y Cochabamba, Bolivia; corresponden a población aymara y quechua respectivamente; desempeñan actividades comerciales vinculadas a la cocina, limpieza, costura, compra y venta de productos; encarceladas por el delito de tráfico de drogas. Algunas de las conclusiones que plantea la investigación es la necesidad de reconocer la autoidentificación y la procedencia territorial como criterios de velar por la calidad indígena en las cárceles de Chile.
\end{abstract}

Palabras clave: Mujeres, cárcel, indígenas, migrantes.

\section{Summary}

The objective of the present article is to characterize the sociocultural profile of foreign indigenous women deprived of liberty in the regions of Arica-Parinacota, Tarapacá and Antofagasta, in northern Chile. For this, a qualitative investigation was carried out by conducting semi-structured interviews. As for the results, most of the women come from the regions of Puno, Peru, and Cochabamba, Bolivia; they correspond to the Aymara and Quechua populations, respectively; they carry out commercial activities related to cooking, cleaning, sewing, buy-and-sale of products; incarcerated for the crime of drug trafficking. Some of the conclusions raised by the research are the need to recognize self-identification and territorial origin as criteria to ensure indigenous quality in Chilean prisons.

Keywords: Women; Jail; Indigenous peoples; Migrants.

1 Antropóloga. Académica (docente e investigadora) y perito de la Defensoría Penal Pública. Escuela de Antropología, Universidad Academia de Humanismo Cristiano, Santiago de Chile. Nacionalidad: chilena. 


\section{Introducción}

La cárcel se ha convertido en una de las tantas instituciones sociales de construcción de género en las sociedades modernas, mediante la implementación de técnicas de control y disciplinamiento de las mujeres privadas de libertad a través de sus cuerpos. El funcionamiento y la organización carcelaria se instituye sobre la base de la opresión, explotación y dominación masculina (Cárdenas, 2011).

La mayoría de los centros de detención femeninos latinoamericanos no cuentan con el espacio adecuado para la población femenina, lo que ha traído, como consecuencias, altos niveles de hacinamiento, falta de sistemas de atención de salud que respondan a las necesidades específicas de las reclusas en embarazos y enfermedades determinadas. Aunque existen cárceles exclusivamente para mujeres, todavía a nivel central el diseño, aplicación y evaluación de los planes, proyectos y programas correspondientes para poder responder a las necesidades de género, son nulos o mínimos y el personal carcelario continúa siendo principalmente masculino (Atabay, 2013).

Para las visitas íntimas se suelen pedir más exigencias a las mujeres que a los hombres. Por otra parte, la poca regularidad en que pueden ver a sus hijos o hijas pone en tensión una estructura familiar monoparental encabezada por mujeres, lo cual genera rupturas familiares y aumenta el nivel de vulnerabilidad de su progenie (Cárdenas, 2011).

En cuanto a las mujeres reclusas extranjeras, las situaciones anteriormente descritas se agudizan, por ejemplo, el acceso a la justicia es aún más limitado; no existe casi contacto con el consulado de su país, instancia fundamental para la comunicación con sus familiares y la satisfacción de ciertos requerimientos que no cubre el sistema carcelario. Los problemas se acentúan por la condición de lejanía y, muchas veces, de desconocimiento por parte de la familia, y por las propias diferencias institucionales entre un sistema judicial y otro.

Actualmente, la población penal femenina del norte de Chile, en las ciudades de Arica, Iquique y Calama, cuenta con un alto porcentaje de mujeres indígenas migrantes, uno de los sectores más desprotegidos en tanto víctimas potenciales de la violencia institucional carcelaria, lo que se evidencia desde el primer control de detención hasta la condena en los casos de hacerse efectiva. Por ejemplo, no se exige la presencia de un ente traductor en el momento del control, por lo que el campo de comprensión de los hechos imputados por parte de las mujeres está absolutamente delimitado por la imposibilidad del mutuo entendimiento (Cárdenas, 2011). En muchos casos se les despoja de sus vestimentas tradicionales, 
ejercicio de negación de su identidad cultural, que deja sus cuerpos al desnudo, expuestos y, por ende, vulnerables.

Por ello, organismos como la Defensoría Penal Pública, creada en el 2003, al alero de la Reforma Procesal Penal, han definido como área prioritaria realizar una investigación que caracterice el perfil sociocultural de estas mujeres con la finalidad de que sirva como base para la elaboración y reformulación de estrategias para la defensa y el abordaje de causas con mujeres indígenas migrantes.

Este artículo tiene por objetivo caracterizar el perfil sociocultural de las mujeres indígenas extranjeras privadas de libertad en las regiones de Arica-Parinacota, Tarapacá y Antofagasta. Es producto de un proceso investigativo solicitado por la Defensoría Penal Pública para sugerir un modelo de identificación y aplicación por parte tanto de la defensoría como de los sujetos facilitadores interculturales, en el abordaje de causas con mujeres que cumplan con estos requisitos.

La investigación se lleva a cabo durante el año 2017 a través de una metodología cualitativa, entiendo por ello una mirada que se centra en los sentidos y significados otorgados por los sujetos en relación con sus vivencias a partir de lo narrativo (Rodríguez, Gil y García, 1996). Se ejecutó como técnica de producción de datos una entrevista semiestructurada realizada a 35 mujeres indígenas extranjeras privadas de libertad de las cárceles de Arica, Iquique, Alto Hospicio y Calama, a través de una pauta temática elaborada por la investigadora responsable. En ests se consideran las inquietudes de las partes facilitadoras interculturales de la Defensoría Penal Pública de todas las regiones del norte grande de Chile.

\section{Género y migración: "Viajamos por necesidad, porque somos las mujeres quienes mantenemos la familia"}

El género constituye una dimensión fundamental a la hora de analizar las dinámicas socioeconómicas y los motivos que determinan la migración de mujeres a Chile y, a su vez, la caracterización de la situación carcelaria como fenómeno multidimensional. Remite al proceso de construcción y reproducción social, cultural y simbólica de la diferencia sexual entre mujeres y hombres; que estructura las identidades y relaciones entre los sexos, delimita roles y atributos, que operan en un contexto de normalización e internalización de las diferencias como naturales (CEPAL, s. f.; Lagarde, 1993; Lamas, 1986).

En estas últimas décadas se ha generado una feminización migratoria, sobre todo transfronteriza, en búsqueda de un nuevo mercado laboral, lo que convierte a las mujeres migrantes en fuentes de remesas para los países de origen, donde se 
encuentran, en la mayoría de los casos, sus familia. Su propósito es la incrementación de recursos económicos asociados a la subsistencia familiar.

La migración transfronteriza en América Latina está determinada por la circularidad de los flujos, esto es, produce un patrón de retorno permanente entre los territorios en que se llevan a cabo las actividades laborales y los de residencia de sus familias, marcado por las responsabilidades y ritos familiares, lo que crea las condiciones de una limitada movilidad laboral dada por la necesidad de regresar constantemente. Esta misma cercanía configura un trabajo femenino de baja calificación y, por otro lado, los altos costos de vida en el país receptor dificultan el retorno cotidiano o la mantención de las relaciones familiares (Godoy, 2007; Mora, 2008).

Los efectos de las migraciones en la reconstrucción de las identidades de género son contradictorias, ya que, por una parte, las nuevas vivencias y los vínculos generados en el país de llegada pueden reproducir estereotipos femeninos del país de procedencia y, a su vez, posibilitar mayores niveles de autonomía y realización personal producto de la ampliación de repertorios interpretativos dados por nuevos marcos de comprensión (Godoy, 2007).

No debemos olvidar que históricamente las fronteras se crearon para delimitar y distinguir a unos grupos de otros, por lo cual operando como muro divisorio, a partir de la diferenciación de identidades sociales. Son siempre reflejo de una geografía política territorial en disputa y de creación de la ciudadanía (Tapia, 2012).

En el norte grande de Chile, la región fronteriza limita con tres países (Argentina, Bolivia y Perú), en un territorio con presencia de comunidades indígenas andinas (aymara y quechua, principalmente), donde habitantes de cada uno de los países han recreado identidades nacionales desde una experiencia de vida marcada por la convivencia con los otros individuos, los del otro lado de la frontera, en un espacio transfronterizo cruzado por diversas rutas ancestrales, de circulación de bienes, personas y comunidades, desde una memoria compartida de haber sido un solo espacio territorial preexistente a los Estados naciones.

La fijación de la frontera nacional desde la Guerra del Pacífico instaura un imaginario social caracterizado por un discurso homogeneizador de lo chileno (Ugarte, 2014), en que lo indígena es asociado con lo extranjero, lo boliviano y lo peruano; por oposición, lo chileno con lo blanco, lo europeo y, por ende, lo civilizado, por lo que las diferencias culturales operarían como diferencia de civilidad, remitiendo lo indígena a lo salvaje. En este marco la chilenización será la única vía posible de modernización, asumiendo una superioridad moral-racial de lo chileno frente 
a lo foráneo, asumido históricamente como el enemigo (Lube Guizardi y Garcés, 2013). A partir de este momento, la base del proyecto identitario nacional será la negación, destrucción e invisibilización de todo componente cultural que ponga en cuestión el ideario de unidad nacional

El Decreto Ley (DL) 1094, de 1975, es el que regula los asuntos relativos a la inmigración en el país, que sitúa exclusivamente la temática como un asunto de extranjería, por lo que no aborda los problemas de la inmigración en Chile, con una orientación policial para evitar supuestamente la entrada de elementos peligrosos o terroristas que amenazaran la estabilidad nacional. Desde esta premisa, el Decreto Ley se encuentra en contradicción con los planteamientos jurídicos y sociales de un Estado Democrático de Derecho (Pérez, Lube Guizardi, Vicuña y Rojas, 2015).

En el 2018, el actual presidente Sebastián Piñera presentó un proyecto de Ley de Migraciones para modificar la actual Ley de Extranjería, proceso que está en curso. Sin embargo el Ejecutivo decretó diversas medidas administrativas mientras dura su promulgación. Estas están centradas en la regularización migratoria a partir de la entrega de visas desde el país de origen, eliminan la posibilidad de solicitud de visa temporal por motivos laborales e inician un período de regularización de quienes hayan ingresado de forma irregular (por pasos no habilitados), el cual ya se encuentra finalizado.

Quienes no presenten solicitudes de regularización dentro del plazo señalado (30 días de corrido desde el 23 de abril) se expulsarán, lo que da cuenta de una ley absolutamente deficiente respecto de los tratados internacionales de resguardo de los derechos de migrantes.

\section{Género y etnicidad: "Me discriminan por mujer, por extranjera pero sobre todo por indígena”}

La dimensión étnica se torna en un elemento central de comprensión de las vivencias de las mujeres indígenas privadas de libertad; remite a diversas acepciones, pero sobre todo se asocia a grupos culturales, minorías o unidades subnacionales en el marco de sociedades con una hegemonía cultural. En cuanto a la dimensión étnica que aborda este artículo nos centramos en el caso indígena.

Para autoras como Leticia Reina (2000), en el contexto actual de globalización, lo étnico es un término en constante redefinición, pero sobre todo una estrategia de lucha política de los pueblos indígenas para combatir desde la diferencia cultural en búsqueda de su legitimación, cuestionando el orden simbólico de la dominación. 
En nuestro sistema judicial, la dimensión étnica ha sido históricamente negada e invisibilizada, además de operar una esencialización respecto de lo indígena como una situación de aislamiento geográfico, de precariedad económica y educativa, como parte de una realidad rural atemporal.

Se construye una imagen purista del indígena como sujeto ahistórico y, por ende, pasivo, sin posibilidad de agenciamiento. El portar apellidos indígenas, ser hablante de lengua indígena o usar vestimenta tradicional serían los únicos indicadores para su reconocimiento como tales y, por ende, la pérdida de algunos de estos elementos implicaría la pérdida identitaria.

En Chile, la Ley Indígena 19.253, creada en 1993, define al ser indígena por descendencia familiar (hasta tercera generación), presencia de un apellido, por matrimonio o adopción, pero también por auto-identificación mediante la validación desde una comunidad o una organización con personalidad jurídica y certificación indígena otorgada por la Corporación Nacional de Desarrollo Indígena.

La autoidentificación es un elemento más de comprensión de la identidad, pero que no ha sido relevante ni tampoco legitimado a la hora de la delimitación de una defensa especializada de una persona imputada que se auto reconoce como tal.

En cuanto a las mujeres indígenas extranjeras, uno de los temas más complejos es la identificación de su calidad indígena más allá de la normatividad chilena. Si bien en nuestro país se reconoce la autoidentificación como un elemento constitutivo de lo indígena, requiere de un proceso de certificación por parte de CONADI que no se ajusta a la realidad de estas mujeres.

La mayoría de las mujeres de esta investigación provienen de Bolivia y Perú, por lo que las legislaciones nacionales pueden ser un referente a considerar a la hora de dar cuenta de su calidad indígena.

En Perú, la calidad indígena remite a tres dimensiones: lengua, territorio y comunidad. La población indígena se define en relación con hogares particulares, cuyo jefe o cónyuge declara poseer lengua materna indígena, por su pertenencia a centros poblados, correspondiendo según la Ley de Demarcación y Organización Territorial a un territorio nacional urbano y rural identificado mediante un nombre y habitado por una población igual o mayor a 151 habitantes en viviendas particulares, o según el Viceministerio de Interculturalidad, por ser uno de los 55 pueblos indígenas catastrados. 
En Bolivia la calidad indígena está determinada por la procedencia de un sujeto de un territorio indígena originario campesino (TIOC), lo cual se aplica a todas las personas pertenecientes a naciones y pueblos con existencia precolonial, quienes en forma colectiva gozan de los derechos consignados en la Constitución Política del Estado Plurinacional de Bolivia.

Cabe destacar que otros referentes que pueden ser utilizados para delimitar la calidad indígena son los diversos tratados y convenios internacionales, entre los que destaca el Convenio 169 de la OIT, promulgado el 2 de octubre del 2008 y en vigencia desde el 5 de septiembre del 2009 por el Estado chileno

La calidad indígena otorgada desde este convenio se da "por el hecho de descender de poblaciones que habitan en el país o en una región geográfica a la que pertenece el país en la época de la conquista o la colonización o del establecimiento de las actuales fronteras estatales y que, cualquiera que sea su situación jurídica, conservan todas sus propias instituciones sociales, económicas, culturales y políticas, o parte de ellas" (Artículo 1 del Convenio 169 de la OIT). La conciencia de su identidad indígena será considerada como un criterio fundamental para determinar los grupos a los cuales se aplican las disposiciones del Convenio

\section{Lugar de origen de las mujeres indígenas extranjeras}

La mayoría de las mujeres entrevistadas en este estudio proceden de dos zonas: Puno, Perú, y Cochabamba, Bolivia, correspondientes a población aymara y quechua respectivamente.

Puno es el nombre tanto de una ciudad, provincia, departamento y región de Perú, ubicada en el corazón de territorio aymara, zona de los antiguos señoríos aymaras Lupacas, Collas y Pacajes, es una provincia fronteriza con Bolivia. Algunas de las localidades o centros poblados de Puno y de origen de las mujeres de este estudio son: Chapalla, Mazo Cruz; Churu Maquera, Collana, Laraqueri, Ilave, Juli, Yanapata Yunguyo, y la ciudad de Desaguadero (zona urbana binacional peruana - boliviana).

Otra de las zonas emblemáticas de origen en relación con Perú es Tacna. Cabe destacar que, en este caso, las mujeres provenientes de esa ciudad no son originarias de ahí, sino más bien su residencia estaría determinada por una migración interna desde la región de Puno a Tacna.

El perfil del sujeto inmigrante que llega a Tacna es el de un puneño aymara proveniente de ámbitos rurales, atraído por nuevos campos de oferta laboral, en un primer 
momento en la mina o actualmente como agricultor, comerciante, en trabajos de construcción y de servicios, o por la posibilidad de realizar trabajos temporales en Arica, Chile, de manera temporal o permanente (Berganza y Cerna, 2011).

En Tacna, la mayoría de aymaras mantendrán diversas prácticas culturales, como por ejemplo actos rituales (challa, tinka) y festividades (anata, fiestas patronales) en barrios y viviendas como estructuración de sentido de vida comunitaria. Complementando estos ritos se articulan lazos fuertes de parentesco entre barrios y distritos. Del mismo modo, nos encontramos con radios comunitarias, organizaciones juveniles, asociaciones barriales, ferias, equipos de fútbol, comparsa de danzantes y músicos, que amplían y consolidan las relaciones sociales y comerciales además de mantener la vigencia de los modos de vida de sus comunidades de origen en la ciudad (Mamani, 2004). En muchos casos, el vínculo directo con los lugares de origen se mantiene, a través de la visita en tiempos de fiesta, el cumplimiento de cargos festivos como de orden político, el envío de dinero, o estadías temporales para desempeñar funciones agrícolas o ganaderas.

En cuanto a mujeres provenientes de Bolivia, la zona de procedencia más frecuente es Cochabamba, que es tanto una ciudad como un departamento. Algunas ciudades y comunidades de origen son: Tarata, Isinuta, Villa Tunari, Pucarita Cocapata, Aiquile, Tiraque, Punata, Chacuela, Apillapampa, Capinota y Quillacollo.

El departamento de Cochabamba cuenta con una variedad de pisos ecológicos de valles, puna y de yungas. Su economía está basada fundamentalmente en el cultivo de tubérculos conjuntamente con la cría de ganado vacuno y ovino. La población es, en su mayoría, de origen quechua y actualmente la organización social gira en torno a los sindicatos campesinos. La economía está basada en la agricultura con cultivos de papa, haba, cebada, oca, maíz, en la zona alta; y bananos, coca, yuca, pina, arroz, cítricos y palmito en la zona baja. La actividad pecuaria se basa en la crianza de ganado ovino y vacuno, y se realiza también la pesca en ríos. La explotación de recursos forestales es otra fuente importante de ingresos, junto a actividades industriales como aserraderos, peladoras de arroz, empacadora de pina y banano y talleres de carpintería. La producción de chicha y tejidos artesanales son de relevancia en la zona alta.

Otras zonas de procedencia en menor escala desde Bolivia son las ciudades y sus respectivas comunidades indígenas de Sucre (estancia Pampa Huasi), Potosí (Cero Gordo, provincia Nor Lípez) y Santa Cruz (ciudad Fernández Alonso), donde también hay una presencia indígena mayoritariamente quechua. 
Tanto entre la población aymara como quechua se desarrolló un sistema de complementariedad ecológica a partir del control vertical de diversos pisos ecológicos (selva, altiplano, precordillera, pampa, valle y costa). Cada pueblo se establecía en una zona nuclear donde se encontraba la mayoría de la población, la administración política y las actividades centrales de producción. En torno a estas zonas, a algunos días de distancia, se establecían islas o archipiélagos de producción de otras plantaciones y cultivos, como la hoja de coca, planta sagrada y medicinal para los pueblos andinos, además de ser áreas de pastoreo de llamas y alpacas, lugares que constituyeron los llamados pisos ecológicos donde las comunidades podían desarrollar otras actividades que el clima y la geografía de la zona nuclear no permitía. Estos espacios eran controlados y cuidados por mitimaes (población indígena desplazada para cumplir con las funciones señaladas), quienes, a pesar de la distancia con sus comunidades de origen, mantenían el lazo comunal y los derechos adquiridos, además de convivir con otros pueblos de la zona, por lo que se convirtían en espacios pluriculturales de diversificación productiva (Murra, 1972).

Este modelo sigue estando vigente hoy entre las comunidades quechua de Bolivia, Chile y Perú, mediante un flujo permanente y transfronterizo, de intercambio de productos, actividades y personas (Fernández, 2013). Es así como, durante diversos momentos del año o en algunas etapas de la vida, comuneros quechua varían de domicilio según los ciclos productivos o como mecanismo de complementación del ingreso familiar, a través del desarrollo de otras actividades laborales que complementen la producción de la chacra, contemplando además que en el departamento de Cochabamba se encuentran tres pisos ecológicos (valles, puna y yungas).

Quizás uno de los puntos a destacar respecto a este ítem es que casi todas las historias de vida de las mujeres entrevistadas dan cuenta de una migración circular permanente desde temprana edad, por razones laborales. Por tanto, mantienen un vínculo con sus comunidades y localidades de origen a través de un retorno permanente para desempeñar actividades productivas temporales, para festividades y para dar cumplimiento a una serie de cargos comunitarios.

\section{Manejo de la lengua indígena}

La lengua es un instrumento de socialización, su adquisición es uno de los procesos fundamentales en que un sujeto se convierte en miembro de su sociedad, refleja las formas en que cada cultura percibe tanto su entorno físico como social y genera una gran influencia en cómo conceptualiza su mundo un sujeto (Hudson, 2000; López, 2000). Al traducir la experiencia individual y colectiva en una lengua, se posibilita la transmisión de una serie de conocimientos y patrones (Fernández, 2003). 
Las lenguas indígenas en América Latina se han constituido históricamente en lenguas oprimidas por ser el medio de expresión de sectores sociales marginados y discriminados. Su situación de opresión deriva del hecho de que sus propios hablantes sufren la misma condición (López, 2000).

Los largos siglos de opresión y marginación han colocado a los pueblos indígenas en una situación de subordinación en casi todos los órdenes de la vida social y esto se refleja en la situación de diglosia, por lo que más que un problema eminentemente lingüístico se trata de un problema político. Se conoce como diglosia a la situación en la que en una sociedad concreta, una o varias lenguas se ven subordinadas a otra que goza de mayor prestigio social en las funciones que cumple. La lengua dominante y de prestigio es utilizada en todos los contextos y ámbitos y constituye un idioma de uso formal; la lengua oprimida y dominada es relegada al plano informal y doméstico. (Fernández, 2003, p. 46-47)

El contexto carcelario sin duda da cuenta de una situación de diglosia, así como también todo el aparataje institucional judicial en Chile. El castellano es casi exclusivamente el único idioma de uso, esto solo ha tenido una pequeña modificación en torno a la defensa de imputados e imputadas indígenas, pues en que algunos casos se ha permitido el rol traductor de los entes facilitadores interculturales o se ha contado con la asistencia de especialistas en lenguas indígenas, pero son pocos casos.

La mayoría de las mujeres entrevistadas son bilingües, manejan tanto el castellano como una lengua indígena, preferentemente el aymara o quechua; sin embargo, existen diversas modalidades de bilingüismo entre ellas. Algunas manejan como lengua materna (L1) el idioma indígena y como lengua segunda (L2) el castellano. En cambio, son muy pocos los casos de monolingüismo en lengua indígena; sin embargo, en la mayoría de los relatos los padres son monolingües y, sobre todo, la madre.

Es importante clarificar que existen además diversos niveles de bilingüismo, desde una condición aditiva hasta una instrumental. Para los autores Siguan y Mackey (1986), la persona bilingüe ideal, llamado bilingüismo aditivo, es quien posee una competencia comparable a su primera lengua de otra, capaz de utilizar una u otra lengua según las circunstancias y con la misma eficacia, estando ante el manejo de dos sistemas lingüísticos en situación de equilibrio. En cambio el bilingüismo instrumental remite a un manejo muy básico de una segunda lengua, que no logra posicionar marcos de comprensión en el sujeto hablante, por lo que no existe una comunicación efectiva. En ese sentido, muchas de las mujeres indígenas extranjeras privadas de libertad, si bien manejan un nivel básico del castellano, no logran 
comprender los mensajes comunicados en este idioma, siendpor lo que resulta necesario, en estos casos, solicitar una persona que traduzca.

Por otra parte, la relación asimétrica entre el idioma oficial y las lenguas indígenas provoca la auto negación de las propias hablantes (Sarto, 1997), por lo que muchas veces, luego de varios meses, producto de un proceso de confianza con el sujeto defensor o facilitador, recién asumen y visibilizan su condición bilingüe.

\section{Contexto familiar de las entrevistadas}

Como anteriormente se señala, la mayoría de los padres de las entrevistadas son hablantes monolingües, quienes no han ingresado al sistema de educación formal o solo cursando los primeros años de enseñanza básica (o primaria).

Llama la atención la gran cantidad de madres viudas de las entrevistadas y la gran cantidad de hermanos o hermanas, lo que refleja la conformación de familias extensivas.

Las principales actividades llevadas a cabo por los padres son la agricultura familiar, en la chacra, y ganadería, ambas de subsistencia y, por ende, para consumo familiar o comunitario. En menor medida realizan laborales comerciales vinculadas a la cocina, limpieza, costura, compra y venta de productos, sin embargo, en el caso de las entrevistadas estas labores serán sus actividades centrales.

En todos los casos, la precariedad laboral será un elemento permanente, ya que no poseen contrataciones laborales y la mayoría de las acciones de comercialización se generan dentro de una economía informal.

En cuanto a la situación familiar actual de las entrevistadas, la mayoría son solteras, viudas o separadas, son las principales sostenedoras económica y emocionalmente de sus familias respectivas, lo que se vincula con los procesos de feminización de la migración, en que migran a países vecinos, como Chile, para aumentar sus ingresos económicos a través de una migración circular, ya que sus hijos o hijas residen en sus países de origen, lo que las obliga a regresar constantemente. En relación con este punto, en los casos investigados, lo que finalmente motiva tanto la migración como la acción delictiva es la generación de mayores ingresos para el tratamiento de enfermedades graves o terminales de sus hijos, parejas o madres.

Sus parejas actuales o anteriores son mayoritariamente indígenas y bilingües, visibilizan diversos contextos de violencia intrafamiliar por parte del conviviente o esposo, por lo que una de las principales causas de es la violencia física y psicológica ejercida por la pareja. 
Respecto del cuidado de la progenie durante la privación de libertad, señalaron que son las madres, hermanas, cuñadas, en unos pocos casos los padres y hasta vecinas del poblado o la comunidad, quienes cumplen ese rol, y casi todos los casos en los países de origen.

En cuanto a la educación formal, la mayoría de las entrevistadas no finalizó sus estudios secundarios, pero sí la primaria.

Finalmente, uno de los ámbitos de recurrencia en el relato de las entrevistadas es el cumplimento de sus padres de algún cargo comunitario, sobre todo del padre, como autoridad política y religiosa o también como figura central en alguna actividad comunitaria, como por ejemplo, corregidor, presidente de la junta, dirigente sindical, capitán del equipo de fútbol, tesorero, etc. Este es un punto central, ya que puede considerarse como otro elemento más que delimite la calidad indígena de las mujeres investigadas, el que algún familiar haya cumplido un cargo dentro del sistema tradicional de representación.

El servicio prestado por un miembro de la comunidad a su colectividad se conoce con el nombre de cargo, abordando las esferas económico-productivas, jurídicas y espirituales, siendo servicios y obligaciones que se cumplen para beneficio de la comunidad en un determinado tiempo (un año por lo general). Son cargos que, en forma secuencial y ascendente, van hacia un proceso creciente de responsabilidad, permitiendo la adquisición de experiencia y conocimiento por parte de quienes lo ejercen (Guzmán, 2011). Quienes realizan los cargos no reciben pago asociado al período de servicio, sino más bien la mayoría de las veces deben invertir tiempo y recursos económicos para realizar sus servicios a la comunidad, a cambio del gran prestigio que le otorga el desempeño de esta labor (Korsbaek, 2009). (Fernández, 2018, p. 586)

En lengua aymara se conoce como thakhi el camino que todo sujeto debe transitar para convertirse en autoridad, a través del cumplimiento progresivo de cargos y responsabilidades públicas. Este proceso se inicia con el matrimonio de una joven pareja, y su conformación como dualidad complementaria, chacha-warmi (hombre-mujer), quienes se convierten en jaqui (persona) a través de esa unión, se les habilita y obliga a cumplir servicios a la comunidad, además de acceder al uso de la tierra (Astvaldsson 1997; Chuquimia, 2006). Para iniciar el thakhi, la pareja se compromete a entrar en la fila o lista para cumplir las obligaciones a la comunidad, bajo un sistema de turnos.

Las autoridades originarias tienen un año para ejercer su cargo. Uno de los primeros cargos a cumplir son los religiosos vinculados a la organización de las fiestas patronales, lo que refleja la articulación entre la dimensión religiosa y política en el 
mundo aymara. Cuando la pareja ha cumplido con los cargos, entran al tiempo de descanso. Algunos son nombrados consejeros especiales dentro de la comunidad, por su prestigio de haber sido autoridad. (Fernández, 2018, p. 587)

\section{Acciones delictivas}

Todas las mujeres indígenas extranjeras entrevistadas están privadas de libertad por el delito de tráfico de drogas. En el caso específico de la muestra de esta investigación, la mayoría de las mujeres se involucran en el tráfico para aumentar sus ingresos económicos, dadas sus precarias condiciones económicas.

Muchas de ellas llegan a Chile previamente para realizar labores agrícolas como trabajadoras por temporada, como parte de una migración circular y permanente. Es frecuente que relaten que, en algún terminal de bus del norte grande, un desconocido les ofrezca trasladar droga a cambio de un pago en dólares, lo que ellas aceptan por la necesidad de aumentar sus recursos económicos para el cuidado de sus familias en su calidad de madres solteras o divorciadas o palear los gastos asociados a enfermedades de algún pariente.

A continuación se presentan algunas citas textuales de las mujeres entrevistadas que reflejan lo anteriormente descrito.

Ese mismo año llegué a Arica a trabajar en una chacra en el Valle de Azapa. Regresé a Tacna y allá una amiga me dice que me vaya a Calama a trabajar con uva. Primero llegué a Iquique y en el terminal un caballero se me acercó para llevar paquetes a Santiago y que me pagaría 500 dólares ... en el sector de Loa la policía hace un control y registro al bus, donde yo llevaba la droga en la cintura.

Cuando estaba viendo mis papeles conocí a otras bolivianas, tiempo en que trabajé de ayudante de cocina por cinco meses. Luego me fui a Bolivia a ver mis hijos, y en mi regreso, en el terminal de Iquique, conocí a una mujer que me ofreció llevar a Vallenar droga por 400 dólares y ella me compró el pasaje. En Loa hemos bajado del bus, estaba haciendo fila y me revisaron, yo llevaba la droga en el estómago (ovoides).

En otros casos, el contacto para trasladar la droga se realiza en el país de origen, a través de un dato de algún pariente o amigo, o simplemente de un desconocido, realizándose la entrega de la droga en el lugar de procedencia o ya en Chile.

Estuve de visita en Cochabamba, a comprar verduras, donde conocí a una mujer tomando chicha. Mi novio la conocía de antes. Ella me ofrece llevar drogas hasta Calama, por lo que mi mamá cuidaría a mis hijos en Tarata. Acepté esto porque necesitaba plata para mis hijos, ya que estaba ganando apenas 30 bolivianos diarios. 
Me fui de viaje desde Cochabamba a Colchane, donde me entregaron la droga. En Quillagua los carabineros nos bajaron encontrando 1 kilo y medio de droga.

En el Terminal de Cocha me habló un caballero y me dijo si llevaba esto hasta la Serena me pagaría 800 dólares. Dejé a mis hijas donde una señora conocida, a quien le tenía que pagar. Tomé junto a otra chica un bus desde Cocha a Oruro, Colchane y en Loa. La droga en polvo estaba abajo del asiento. En Loa bajé y al regresar al bus saqué lo que llevaba.

Me vine a Chile como mi prima, ya había venido una vez antes a Santiago. Nos juntamos con dos chicos desde Cocha, pasamos por Oruro, Colchane hasta llegar a Iquique. Nos dijeron que desde Iquique nos fuéramos a Copiapó y de ahí a Santiago. Finalmente nos fuimos los cuatro hasta Calama y en la salida nos encontraron la droga. Cuando nos revisaron en Calama le preguntaron a uno de los chicos donde iba pero no sabía por lo que yo contesté y nos hicieron bajar a los 4 . Nos encontraron ovoides, uno de los chicos había vomitado y dejado todo en una bolsa negra.

Vine a Cochabamba de vacaciones y ahí conocí a un amigo, quien me ofrece llevar droga a Chile. Acepto la oferta. Le miento a mi marido para ir a Chile y le digo que vengo por mercadería para luego vender. Viajo hasta Iquique (Cocha, Oruro y Pisiga) para llegar a Calama, al salir de ahí me revisan, yo iba a Santiago. Viajé con una prima, y llevábamos pasta base en las zapatillas.

Si bien en muchos de los casos de imputadas por tráfico de drogas ellas desconocen el porte, ya que es la pareja quien realiza el tráfico o por engaño de algún desconocido al solicitar trasladar algún bulto, en este trabajo son pocos los casos que reflejan esta situación.

\section{A modo de cierre}

La investigación nos plantea como principal desafío pensar un proceso de identificación de lo indígena más allá de su certificación, incluyendo las recomendaciones que los tratados y convenios internacionales señalan al respecto, como el Convenio 169 de la OIT, además de solicitar información a los consulados respectivos a modo de complementación. En este sentido es fundamental reconocer la autoidentificación como un criterio más de reconocimiento, además de considerar los apellidos y otros indicadores que aquí fueron expuestos, como la procedencia territorial, la lengua indígena de uso, los antecedentes familiares, las costumbres, entre otros. Si fuese necesario una identificación formal (certificado calidad indígena) pueden ser utilizados como referentes instrumentos legales nacionales, dispositivos internacionales, además del DNI o cédula de identidad. 
La procedencia territorial en los casos de mujeres provenientes de Bolivia y Perú es uno de los elementos pilares para definir su condición indígena, por lo que es necesario precisar los términos centro poblado, ayllu, pueblo o parcialidad de nacimiento en la primera entrevista realizada por quien la defiende, el pueblo o la comunidad de origen tanto de la familia como la propia, . Por otra parte, es fundamental asumir como parte de la historia personal y territorial los flujos migratorios campo-ciudad, especificando lugares permanentes o momentáneos de residencia (tanto personales como familiares).

El registro del uso de la lengua indígena por parte de las mujeres encarceladas, su familia y en el caso de aplicarse su cónyuge, es otro de los puntos centrales para la caracterización de la calidad indígena; sin embargo, se debe precisar el carácter monolingüe o bilingüe, según cada caso; pero, además, el tipo de bilingüismo (si es aditivo o instrumental), por lo que se requiere un informe lingüístico al respecto para analizar la necesidad de apoyo en esta materia, tanto de la facilitadora intercultural o de especialista.

La participación familiar y personal en el sistema de autoridades originarias en los cargos políticos comunitarios, locales o religiosos, para el caso de las mujeres andinas, es otro de los elementos a tener en cuenta, ya que reflejan su participación en la estructura comunitaria, a pesar de existir una constante migración campo - ciudad (y viceversa). Esta información se complementa con la descripción de actividades económicas comunitarias, familiares y personales, los usos y costumbres como prácticas ceremoniales, ritualidades y festividades, en que participan de manera directa o indirecta.

La configuración de una defensa especializada indígena requiere de un proceso que vaya más allá de lo netamente formal sino desde lo cotidiano, las visitas, la realización de las entrevistas, saludo según los usos, considerando la experiencia que poseen las facilitadores interculturales. También requiere de la generación de una estrategia multidisciplinar e intercultural de defensa y la aplicación de un enfoque transnacional/transfronterizo, a través de un trabajo articulado con los diversos consulados y oficinas de defensa especializada de los países de origen de las imputadas y condenadas, como por ejemplo la Defensa de Pueblo o de la Mujer en Bolivia. En esta misma dimensión se sugiere operar con un enfoque de género de defensa en que la reconstrucción de las relaciones de géneros en su espacio comunitario sea un elemento a considerar en el mismo abordaje de la causa.

Se debe potenciar el carácter oral y visual del soporte. En el norte grande se han realizado algunas experiencias de difusión por parte de las facilitadoras interculturales con líneas del tiempo en que visualmente se plasman los diversos momentos 
en que cada imputada se encuentra. Por otro lado, la realización de entrevistas grupales entre pares (por lengua, pueblo, territorio, etc.) puede potenciar la identificación de ejes discursivos sociales, y crea un mayor insumo para la construcción de la estrategia de defensa.

\section{Referencias}

Amselle, J. L. (1985). Ethnies et espaces : pour une anthropologie topologique, en Amselle, Jean Loup y M`Bokolo, Elikia, Ethnies, tribalisme et état en Afrique. París: La Découverte.

Atabay, T. (2013). Mujeres privadas de libertad: Una guía para el monitoreo con perspectiva de género. Asociación para la prevención de la tortura y Reforma Penal Internacional. Londres: Reforma Penal Internacional.

Arias, A. y Polar, O. (1991). Pueblo aymara: Realidad vigente. Lima: Instituto de Pastoral Andina.

Astvaldsson, A. (1997). Las voces de los waka: Fuentes principales del poder político Aymara. La Paz: Cuadernos de Investigación 54 (CIPCA).

Barth, F. (1976). Los grupos étnicos y sus fronteras. La organización social de las diferencias culturales, México: FCE.

Berganza, I. y Cerna, M. (2011). Dinámicas migratorias en la frontera Perú-Chile. Arica, Tacna e Iquique. Lima: Departamento Pastoral de Movilidad Humana.

Cárdenas, A. (2011). Mujeres y cárcel en Chile: Diagnóstico de las necesidades de grupos vulnerables en prisión, Santiago de Chile: Universidad Diego Portales-ICSO. Disponible en https://www. icso.cl/wp-content/uploads/2012/01/Proyecto-Grupos-Vulnerables-CPF-GIZ-MINJU-ICSO-versión-final-para-página-web-Diciembre-2011.pdf

Comisión Económica para América Latina y el Caribe (CEPAL). (s. f.). Mujeres en América Latina. México: Fondo de Cultura Económica.

Chuquimia, R. G. (2006). Repensando la democracia desde el ayllu. De la condición democrática en crisis a la idea de comunidad en la política. La Paz: Editorial Independiente.

Diesbach De Rochefort, N. (2002). Frontera: ¿Muro divisorio tejido de relaciones? Estudios Fronterizos, 3(5), 9-42. México: Universidad Autónoma de Baja California.

Fernández, F. (2003). Hacia la construcción de una educación pertinente: La educación intercultural bilingüe en la primera región (Tesis para optar al grado de Antropóloga). Universidad Academia de Humanismo Cristiano, Chile. 
Fernández, F. (2013). Entre la indianización y la municipalización de lo indígena: Estado y comunidad en Bolivia y Chile (Tesis de doctorado). Universidad de Santiago de Chile, Instituto de Estudios Avanzados IDEA, Chile.

Fernández, F. (2018). Municipio, sistema de cargo y autonomía indígena en Bolivia: El caso de Jesús de Machaca, departamento de La Paz. The Journal of Latin American and Caribbean Anthropology, 23(3), 579-592. EEUU: Universidad de Indiana.

Godoy, L. (2007). Fenómenos migratorios y género: Identidades femeninas "remodeladas". Psykhe, 16(1), 41-51.

González, S. (2009). El Norte Grande de Chile y sus dos Triple-Fronteras: Andina (Perú, Bolivia y Chile) y Circumpuneña (Bolivia, Argentina y Chile). Cuadernos Interculturales, 7(13), 27-42. Chile: Universidad de Playa Ancha.

González, S., Ovando, C. y Rouviere, L. (2008). De "Aymaras en la frontera" a "Aymaras sin fronteras". Los gobiernos locales de la triple-frontera andina (Perú, Bolivia y Chile) y la globalización. Diálogo Andino, 31, 31-46. Chile: Universidad de Tarapacá.

Guzmán, O. Q. (2011). Apuntes acerca del sistema de cargos en los ayllus bolivianos. Temas Sociales, 31, 201-241. Bolivia: Universidad Mayor de San Andrés.

Hudson, R. (2000). La sociolingüística, Barcelona: Editorial Anagrama.

Korsbaek, L. (2009). Introducción crítica al sistema de cargos. Disponible en https://justiciaypluralidad.files.wordpress.com/2013/11/cuaderno-ii-rybertt-total.doc

Lagarde, M. (1993). Los cautiverios de las mujeres: Madresposas, monjas, putas, presas y locas. México: Universidad Nacional Autónoma de México.

Lamas, M. (1986). La antropología feminista y la categoría de género. Nueva Antropología, 8(30), 173-198. México.

López, L. E. (2000). La cuestión de la interculturalidad y la educación latinoamericana, texto. Seminario Análisis de Perspectivas de la Educación en América Latina, UNESCO, Chile.

Lube Guizardi, M. y Garcés, A. (2013). Circuitos migrantes. Itinerarios y formación de redes migratorias entre Perú, Bolivia, Chile y Argentina en el norte grande chileno. Papeles de Población, 1(78), 65-110. México: Universidad Autónoma del Estado de México.

Lube Guizardi, M., Pérez, C., Martínez, I. y Jordán, D. (2015). Normativa legal de la migración en Chile: Marcos y definiciones jurídicas aplicables a la región de Arica y Parinacota. En Vicuña, José Tomás y Rojas, Tomás, Migración en Arica y Parinacota: Panoramas y tendencias de una región fronteriza. Chile: Ediciones Universidad Alberto Hurtado. 
Mora, C. (2008). Globalización, género y migraciones. Revista Polis, 7(20), 285-297. Chile: Universidad Bolivariana.

Murra, J. (1972). Formaciones económicas y políticas del mundo andino. Lima: Instituto de Estudios Peruanos Ediciones.

Murra, J. (1988). El aymara libre de ayer. En X. Albó (Ed.), Raíces de América: El Mundo Aymara. Madrid: Ediciones Alianza/UNESCO.

Pease, F. (1981). Continuidad y resistencia de lo andino, Cuzco: Instituto de Pastoral Andina.

Reina, L (Coord.). (2000) Los retos de la etnicidad en los Estados-nación del siglo XXI. México: Ciesas/INI/Porrúa.

Rodríguez, G., Gil, J. y García, E. (1996). Metodología de la investigación cualitativa. Granada: Aljibe.

Sarto Martín, M. P. (1997). El bilingüismo: Una aportación a las necesidades educativas lingüísticas. Salamanca: Amarú Ediciones.

Siguan, M. y Mackey W. F. (1986). Education et bilinguisme. Paris: UNESCO - Delachaux et Niestlé.

Tapia, M. (2012). Frontera y migración en el norte de Chile a partir del análisis de los censos de población. Siglos XIX-XXI. Revista de Geografía Norte Grande, 53, 177-198. Chile: Pontificia Universidad Católica de Chile. Instituto de Geografía.

Ugarte, E. J. (2014). La Guerra del Pacífico como referente nacional y punto condicionante de las relaciones chileno-peruanas. Si Somos Americanos, 2, 15, 159-185. Chile: Universidad Arturo Prat.

Vicuña, J. T. y Rojas, T. (Ed.) (2015). Migración en Arica y Parinacota: Panoramas y tendencias de una región fronteriza. Chile: Ediciones Universidad Alberto Hurtado. 